\title{
FORÇA VERSUS REPRESENTAÇÃO: $O$ LEGADO DE NIETZSCHE NA FILOSOFIA DE GILLES DELEUZE
}

\author{
Maurício Mangueira* \\ mauriciomangueira@infonet.com.br \\ Eduardo Maurício da Silva Bonfim** \\ edu.mauricio@bol.com.br
}

RESUMO É inegável a influência que a obra de Nietzsche exerceu na filosofia de Deleuze. Inaugurando, de certo modo, um novo estilo de pensamento na cultura do Ocidente, Nietzsche conferiu novas interpretações a certos conceitos filosóficos considerados imutáveis e eternos, como os conceitos de verdade, de essência e de força. Utilizando-se da tipologia de forças nietzschianas, Deleuze nos mostra como o saber do Ocidente se funda em um pensamento que o filósofo francês denominará de representacional, em oposição a um pensamento da diferença, elucidando como estas duas formas de conhecer se correlacionam a tipos distintos de forças. Assim, o conceito de força cunhado por Nietzsche permitirá a Deleuze não somente traçar uma crítica ao saber ocidental - predominantemente representacional -, como também desenvolver sua própria filosofia da diferença, profundamente influenciada pela crítica e pelo perspectivismo nietzschianos.

Palavras-chave Força, representação, diferença, Deleuze, Nietzsche.

* Professor associado da Universidade Federal de Sergipe.

** Mestre em Psicologia Social pela Universidade Federal de Sergipe. Artigo recebido em 12/04/2013 e aprovado em 20/10/2013.

KRITERION, Belo Horizonte, no 130, Dez./2014, p. 619-635 
ABSTRACT The influence of Nietzsche's work in Deleuze's philosophy is undeniable. Starting a new style of thinking in the western culture, Nietzsche gave new interpretations to certain philosophical concepts considered immutable and eternal, like the concepts of truth, essence and force. Using Nietzsche's typology of forces, Deleuze shows us how the western knowledge is constituted by a thought the French philosopher calls representational, as opposed to a thought of difference, elucidating how these two ways of knowledge relate to different types of forces. Therefore, the concept of force, created by Nietzsche, allows Deleuze to draw a criticism on western knowledge and also to develop his own philosophy of the difference, deeply influenced by the critic and perspectivism of Nietzsche's philosophy.

Keywords Force, representation, difference, Deleuze, Nietzsche.

\section{Pensamento e conhecimento}

Sabe-se que um dos temas mais importantes na démarche filosófica de Gilles Deleuze é pensar uma filosofia da diferença por ela própria, o que implica, de antemão, uma crítica ao pensamento representacional. Esta questão encontra-se profundamente articulada à problemática do conhecimento, visto que, da perspectiva do filósofo francês, um pensamento da representação e um pensamento da diferença implicam formas distintas de conhecer, na medida em que exigem do pensamento, ou das forças que o constituem, modos distintos de avaliação dos diversos fenômenos, como veremos mais adiante.

Em contrapartida, é fácil constatar que Friedrich Nietzsche é, sem sombra de dúvidas, um dos principais intercessores de Deleuze em seu percurso. Além de ter dedicado dois de seus livros ao pensador alemão - "Nietzsche e a filosofia" (1976) e "Nietzsche" (2007) -, são inúmeros os textos em que Nietzsche se apresenta como um dos seus principais interlocutores. Sem dúvida isto se deve ao fato de que dois dos principais alvos de Nietzsche ao longo de sua obra são justamente o modo de conhecer predominante na cultura do Ocidente - marcadamente representacional - e a dialética hegeliana - considerada por Deleuze como uns dos principais expoentes desse modelo da representação ou pensamento representacional ${ }^{1}$-, apesar da sua incorporação do tempo e das transformações da natureza.

1 Em muitos de seus trabalhos Deleuze buscou elucidar as principais características do modelo da representação, visto que, ao longo de sua obra, o filósofo francês se dedicou à constituição de um 
Neste sentido, podemos nos perguntar de que modo as ideias de Nietzsche são importantes a Deleuze em sua crítica à representação. Assim, neste artigo, objetivamos expor um dos vetores que consideramos dos principais: a importância do conceito de força na realização de uma filosofia da diferença.

\section{O conceito de força e o pensar enquanto força atribuidora de sentido}

Talvez seja impossível falar da filosofia nietzschiana sem mencionar o conceito de força. Em "Nietzsche e a filosofia", segundo livro publicado por Deleuze, o filósofo francês nos mostra como este conceito possui uma importância capital na obra do filósofo alemão, articulando-se com outros importantes conceitos, como os de sentido e valor, conceitos importantíssimos na concepção do conhecimento ou da qualidade deste, e na direção das condutas dos homens. A junção desses conceitos, segundo Deleuze, permitirá a Nietzsche desenvolver aquilo que seria o traço original de sua obra: o seu projeto de conceber o conhecimento, ou sua busca, como valor e, consequentemente, a crítica ao conhecimento enquanto crítica ao valor, e a crítica dos valores a partir da crítica à qualidade da força que os cria e que sustenta essa démarche.

A cultura ocidental se fez e ainda se faz pelo querer ou desejo de encontrar ou constituir para si conhecimentos, mas não qualquer conhecimento. Buscam-se conhecimentos que sejam verdadeiros, e nesta caminhada uma das principais questões, senão a principal, diz respeito às concepções que o sujeito cria para si ao obter ou constituir seus conhecimentos. As buscas e seus resultados sempre foram colocados em termos de adequação, descoberta ou desvelamento de algo que seria a realidade. Já no que diz respeito ao sujeito, as ideias sempre foram pensadas em termos de cópias ou representações de algo ou de alguém. Nietzsche, por seu lado, no interior desta problemática, vem introduzir os conceitos de sentido e valor, ambos relacionados aos conceitos de corpo e força como elementos que não devem ser menosprezados nesta busca do conhecimento, mas, ao contrário, devem ser privilegiados.

pensamento da diferença que se contrapunha a um pensamento representacional. Em suas análises, Deleuze nos mostra de que modo o pensamento representacional tece estreitos vínculos com o senso comum - caracterizado por seu comprometimento com a busca do Mesmo, das verdades universais e atemporais -, bem como com o seu correlato, a recognição. Em "Diferença e repetição" (2009), o filósofo nos aponta como o senso comum seria responsável não só por construir uma imagem do pensamento na qual este se apresenta como naturalmente propenso ao conhecimento, mas também por conferir uma natureza a priori às coisas, atribuindo-lhes uma essência. Ou seja, o senso comum se encarregaria de construir uma representação universal, imutável, do que seria o pensamento e as coisas. 
Mas como Nietzsche pensa esta questão? Pensar o conceito de força para Nietzsche é, na verdade, pensar em forças. Uma força, segundo o pensador alemão, se define pelo complexo de relações que ela mantém com outras forças, e é justamente dessa interação entre diferentes forças que os mais variados corpos são produzidos. Dito de outro modo, um corpo ou um objeto nada mais é do que a expressão ou produto de um determinado conjunto de forças em um dado momento.

Não há objeto (fenômeno) que já não seja possuído, visto que, nele mesmo, ele é, não uma aparência, mas o aparecimento de uma força. Toda força está, portanto, numa relação essencial com uma outra força. O ser da força é o plural; seria rigorosamente absurdo pensar a força no singular. Uma força é dominação, mas é também o objeto sobre o qual uma dominação se exerce. (Deleuze, 1976, p. 5)

Neste sentido, podemos afirmar que não só o fenômeno - objeto - é força, mas também que o conhecedor, isto é, o sujeito de conhecimento, é um corpo, e como tal, produto ele também de forças. Isto significa dizer que não somente o objeto (enquanto fenômeno), como também o sujeito (enquanto corpo pensante) são antes de tudo um conjunto de forças. É exatamente este caráter criador e plural da força em Nietzsche que fará esse conceito adquirir tamanha importância na filosofia de Deleuze. Afinal, afirmar uma pluralidade de forças na constituição de um dado fenômeno - seja ele objeto ou sujeito é, por conseguinte, afirmar a pluralidade do próprio fenômeno. Desse modo, um "mesmo" fenômeno pode apresentar diversos sentidos, dependendo das forças que estejam nele presentes bem como daquelas que se apropriam dele no momento. Aqui já vemos se desenhar a nítida correlação entre os conceitos de força e de sentido: na determinação do sentido de alguma coisa importa a determinação ou qualidade das forças que estão prevalecendo ou sobressaindose neste processo de determinação.

Este modo de entender a produção de sentido de algo ou alguém nos apresenta, em verdade, a importância de outra característica fundamental da filosofia nietzschiana do conhecimento: a interpretação. Ora, se um fenômeno e sujeito são forças, a determinação do sentido de um fenômeno não está separada das forças que entram em contato com o fenômeno, produzindolhe um sentido, isto é, dando-lhe uma interpretação. E esta é produzida pelas forças que compõem o corpo do sujeito da interpretação. Este privilegiará uma ou algumas das forças que compõem o fenômeno, em função das forças que compõem ele próprio. Este caráter interpretativo do corpopensamento-força em Nietzsche é, com certeza, uma das ideias que maior impacto provocou no percurso filosófico de Deleuze. No entanto, ela não é 
uma ideia simples. Podemos dizer que todo corpo, seja ele um animal, uma planta, o homem, uma ideia, etc., ao entrar em contato com outro corpo, sempre realiza uma interpretação deste corpo em função das forças que o constituem e que o dominam naquele momento, e que possibilitam ou não o entrar - e a forma de entrar - na própria relação. Na deriva do homem em sua busca pelo conhecimento, a linguagem, isto é, a força e a organização das palavras, adquirem certa importância, a ponto de erroneamente considerarmos interpretação como interpretação linguística, oral ou escrita.

Para Deleuze, o pensador - quiçá todo e qualquer sujeito humano - é um atribuidor de sentido, é aquele capaz de interpretar diversos tipos de signos, algumas das diversas forças existentes em um fenômeno, com a condição que não esqueçamos que nele são as suas forças que estão a produzir o sentido. Quando algo aparece, quando algo emerge dotado de certa natureza ou identidade, esta natureza não é a da essência do objeto, e sim aquilo que emergiu do encontro e ação de determinadas forças.

Jamais encontraremos o sentido de alguma coisa (fenômeno humano, biológico ou até mesmo físico) se não sabemos qual é a força que se apropria da coisa, que a explora, que dela se apodera ou nela se exprime. Um fenômeno não é uma aparência, nem mesmo uma aparição, mas um signo, um sintoma que encontra seu sentido numa força atual. A filosofia inteira é uma sintomatologia, uma semiologia. As ciências são um sistema sintomatológico e semiológico. (Deleuze, 1976, p. 3)

Por ora não nos perguntemos a respeito destas forças que se apropriam e fazem emergir um sentido. Sendo o fenômeno uma expressão de forças que se apropriaram de certas forças, podemos dizer que a história da humanidade é uma história dessas apropriações, dessas atribuições de sentido. Mas é possível conhecermos quais são essas forças que atribuem sentido ou, ao menos, algumas dessas forças? Nos homens, as forças em consonância com a linguagem e a vida criam valores, o que é bom ou ruim, o que é bem ou mal. Mas essas criações/nomeações dos valores expressam apenas as forças que compõem os corpos que os expressam.

É neste sentido que Deleuze nos diz que toda interpretação, de forma geral, é uma avaliação. Mas, ao avaliar, quem avalia sempre o faz de acordo com determinados valores que já são expressões das forças que o constituem.

Assim, avancemos mais um passo na teoria nietzschiana: vimos que as forças apresentam uma pluralidade de sentidos, mas o sentido, por sua vez, implica o conceito de valor. O pensador, o filósofo ou qualquer homem carrega consigo certos valores que determinarão o modo como ele avalia um fenômeno. A importância do valor para a crítica nietzschiana diz respeito ao fato de que esse conceito introduz na filosofia ocidental o ponto de vista 
diferencial por meio do qual os próprios valores serão avaliados. Isto significa dizer que os valores, eles mesmos, já são efeitos de avaliações. Só é possível atribuir valores a partir de uma avaliação, de uma determinada perspectiva. Em contrapartida, podemos nos perguntar quais as condições que produzem ou possibilitam as próprias avaliações. Será que devemos cair num círculo vicioso que afirmaria que os valores criam avaliações que pressupõem valores, etc.? Quais são então as condições que fundam os valores e as avaliações? Não existiria algo mais básico que daria alma e corpo aos valores e às avaliações?

É por isto que Nietzsche nos fala em valores ou avaliações altas ou baixas, nobres ou mesquinhas. Não se pode separar os valores e as avaliações de um determinado modo de vida, de uma maneira de viver. Quando avalia alguma coisa, o pensador necessariamente a considera de acordo com a sua perspectiva, privilegia certas forças que, em última instância, se compõem com suas próprias forças, com a sua própria maneira de pensar. Se todo corpo é um produto de forças, é óbvio que o pensador se constitui, ele próprio, em uma pluralidade de forças dotadas de um sentido. Ao interpretar um fenômeno, é inevitável, então, que o filósofo tente se apropriar dele, conferindo-lhe um sentido ou novos sentidos.

As avaliações, referidas a seu elemento, não são valores, mas maneiras de ser, modos de existência daqueles que julgam e avaliam, servindo precisamente de princípios para os valores em relação aos quais eles julgam. Por isso temos sempre as crenças, os sentimentos, os pensamentos que merecemos em função de nossa maneira de ser ou de nosso estilo de vida. Há coisas que só se pode dizer, sentir ou conceber, valores nos quais só se pode crer com a condição de avaliar "baixamente", de viver e pensar "baixamente". Eis o essencial: o alto e o baixo, o nobre e o vil não são valores, mas representam o elemento diferencial do qual derivam o valor dos próprios valores. (Deleuze, 1976, p. 1, grifos no original)

Esta correlação existente entre o pensamento e a vida é outra característica inevitável e central da filosofia de Nietzsche, característica que Deleuze utilizará na composição do seu próprio sistema filosófico. Nietzsche talvez tenha sido o filósofo que melhor ressaltou a problemática existente entre pensamento e política, esta última entendida justamente enquanto afirmação de um determinado modo de vida ou de viver. É a isto que Deleuze se refere quando nos fala de um elemento diferencial do qual derivaria o valor dos valores. Este elemento não seria outra coisa senão a vida do pensador: é a vida quem avalia, em último caso, os valores. Ela é o elemento que decidirá se um determinado valor ou um determinado pensamento convém a sua afirmação ou a sua própria destruição. Assim, encontramos em "Nietzsche": 
O filósofo do futuro é ao mesmo tempo o explorador dos velhos mundos, cumes e cavernas, e só cria à força de se lembrar de qualquer coisa que foi essencialmente esquecida. Esta qualquer coisa, segundo Nietzsche, é a unidade do pensamento e da vida. Unidade complexa: um passo para a vida, um passo para o pensamento. Os modos de vida inspiram maneiras de pensar, os modos de pensar criam maneiras de viver. A vida activa o pensamento e o pensamento, por seu lado, afirma a vida. (Deleuze, 2007, p. 18, grifos no original)

É por este motivo que Nietzsche afirmará que ele foi o único filósofo até então a conduzir uma verdadeira crítica dos valores, já que todos os projetos anteriores de crítica falharam exatamente neste aspecto, em não considerar o elemento diferencial dos valores, o seu elemento criador, isto é, a própria vida ou os modos de viver do pensador. A crítica diz respeito, então, não a uma crítica dos valores existentes: fazer uma crítica dos valores não é fazer um inventário de todos os valores, denunciando aquilo que supostamente seriam os falsos valores e exaltando os verdadeiros. Essa é a crítica comum, encontrável mesmo em toda perspectiva revolucionária: "Eu na verdade, você no erro!".

Ao contrário, uma crítica dos valores só pode dizer respeito a uma crítica das forças que estão na origem da sua criação: de que perspectiva ou de que ponto de vista um determinado valor se apresenta como superior, quais modos de vida ou de viver permitiram a sua criação, ou ainda, de forma perspectiva, quais possibilidades de vida ele cria. É neste ponto que encontramos o limite de uma perspectiva representacional. A vida ou os modos de vida, as forças que os ensejam, são o que há de irrepresentável. A vida e o viver são inevitavelmente imanentes aos corpos/forças que compõem a própria vida/ viver. A vida e o viver de um corpo jamais podem ser vistos e vividos do exterior, representacionalmente, e caso isso venha a ser feito já seria efeito de um certo viver, de um certo estilo de vida. E se a crítica diz respeito à criação e não à representação é justamente porque ela se refere à vida como elemento diferencial da criação de valores.

Seguido este raciocínio, torna-se evidente que o pensamento deixa de ser na sua nascente um ato reflexivo, e nos deparamos com um tipo de conhecimento que não é reconhecimento ou representacional. Não se trata mais de reconhecer valores tidos como superiores e sim de criação e afirmação de valores, criar modos ou possibilidades de vida. Deleuze nos mostra como o problema do conhecimento em Nietzsche passa necessariamente por essa questão: em determinado momento da história do Ocidente, o conhecimento tomou a dianteira, se naturalizou, passou a ser considerado como um fim em si mesmo, subordinando assim o pensamento e a própria vida, opondo-se à própria vida e ao pensamento. Mas não qualquer conhecimento. Ou seja, em 
dado momento histórico, atribuíram-se ao conhecimento valores superiores à própria vida, valores que deveriam ser reconhecidos como verdades, estas, superiores à própria vida. É precisamente a isto que a crítica nietzschiana dos valores se refere: é necessário investigar qual modo de vida quer um conhecimento que seja superior a si, que atribui ao conhecimento um valor superior a ela mesma, quais forças exigem do pensamento uma atividade puramente recognitiva.

Mas, ao realizar a crítica à busca pelo conhecimento verdadeiro - de Sócrates até Hegel - e ao modo de vida que o instituiu ou o institui, Nietzsche está trazendo para o Ocidente um novo sentido que toma para si o pensar e o próprio conhecer.

Mas então a crítica, concebida como crítica do próprio conhecimento, não exprimiria novas forças capazes de dar um outro sentido ao pensamento? Um pensamento que iria até o fim do que a vida pode, um pensamento que conduziria a vida até o fim do que ela pode. Em lugar de um conhecimento que se opõe à vida, um pensamento que afirme a vida. A vida seria a força ativa do pensamento, e o pensamento seria o poder afirmativo da vida. Ambos iriam no mesmo sentido, encadeando-se e quebrando os limites, seguindo-se passo a passo um ao outro, no esforço de uma criação inaudita. Pensar significaria descobrir, inventar novas possibilidades de vida. (Deleuze, 1976, p. 83)

Mas a palavra vida não nos diz muito, pois todos os seres humanos são seres vivos. Além do mais, não existe apenas um modo de vida, mas vários modos.

\section{Genealogia das forças e do pensamento}

Já vimos que, do ponto de vista de Nietzsche, o filósofo ou força pensante deve ser capaz de interpretar os diversos fenômenos, conferindo-lhes um sentido, ideia que será retomada por Deleuze em seu próprio percurso filosófico. Desse modo, o triunfo de um tipo de conhecimento que se pressupõe superior à própria vida ou viver deve ser encarado como um sintoma de algo, como o domínio de certas forças. Para Nietzsche este sintoma seria a predominância, na cultura ocidental, de um determinado tipo de forças: existem forças ou modos de viver que são responsáveis por depreciar a vida, subjugando-a a valores considerados superiores. Mas também haveria outro tipo de forças responsáveis por afirmar a vida, considerando-a como princípio último de avaliação.

Aqui podemos perceber mais uma vez a importância do pensamento de Nietzsche para Deleuze. Utilizando-se da tipologia nietzschiana das forças, 
o filósofo francês mostrará que, se é verdade que existe uma intrínseca correlação entre vida e pensamento, haveria forças que exigiriam uma atividade de recognição no pensamento, bem como forças que desencadeariam no pensamento outro tipo de atividade: não mais uma atividade puramente contemplativa e rememorativa, mas um procedimento criativo por meio do qual um pensamento afirma a sua força-diferença e a própria vida. É claro que, de certo modo, já podemos encontrar esta ideia presente na obra de Nietzsche. No entanto Deleuze a desenvolverá conferindo-lhe novos contornos.

Em "Nietzsche e a filosofia", Deleuze nos apresenta a tipologia das forças tal qual pensada por Nietzsche. De acordo com o pensador alemão, as forças seriam de dois tipos: ativas e reativas. A principal distinção entre elas é que as forças ativas se caracterizam por seu poder de criar e desenvolver novas formas, sendo consideradas por Nietzsche como forças superiores. As forças reativas, por sua vez, seriam forças predominantemente de conservação e adaptação, e por isso inferiores. Não devemos esquecer que as forças reativas, mesmo sendo inferiores, continuam sendo forças. Se Nietzsche as considera como forças inferiores isso se deve ao fato de que elas só podem ser pensadas levando-se em consideração as forças superiores ou ativas, como explicitaremos mais adiante.

Mas cada vez que marcamos assim a nobreza da ação e sua superioridade sobre a reação, não devemos esquecer que a reação designa um tipo de forças tanto quanto a ação, com a ressalva de que as reações não podem ser captadas nem compreendidas cientificamente como forças se não as relacionarmos com as forças superiores que são precisamente de um outro tipo. Reativo é uma qualidade original da força mas que só pode ser interpretada como tal em relação com o ativo, a partir do ativo. (Deleuze, 1976, p. 35)

Ressaltar que as forças reativas não perdem sua condição de força é importante pelo seguinte fato: a característica principal de qualquer força, seja ela ativa ou reativa, é estabelecer sua diferença em relação às outras forças por meio de uma ação. Agir é a propriedade essencial de toda e qualquer força, mesmo que essa ação seja, em última instância, uma re-ação. Assim, existiria tanta ação na força reativa quanto na ativa, com uma diferença: na força ativa a ação possui um caráter de afirmação, de devir. Já na força reativa a ação possui um caráter de negação, de conservação. A ação das forças reativas é na verdade uma negação às forças ativas, uma re-ação a essas forças, um travamento. As forças reativas agem separando as forças ativas do que elas efetivamente podem. É por isso que, de uma perspectiva nietzschiana, as forças reativas são inferiores. Se elas não podem ser pensadas sem se levar 
em consideração as forças ativas é justamente porque sua ação é uma re-ação a esse outro tipo de forças.

Os termos afirmação e negação, utilizados acima para definir o caráter das forças, nos levam a outro conceito essencial da filosofia de Nietzsche: a vontade de poder. Em seus livros dedicados à obra do filósofo alemão, Deleuze nos mostra todo o tipo de controvérsias geradas por esse conceito. Entretanto, o filósofo francês se detém mais especificamente a uma delas: a vontade de poder não poderia significar querer o poder, desejar o poder, querer dominar outros, pelo menos em uma perspectiva nietzschiana. Devemos lembrar que aquilo que interessa ao pensador alemão é investigar quais forças, quais formas de vida puderam originar determinados valores. $\mathrm{Ou}$ mais ainda, de que ponto de vista um determinado valor pode ser considerado como superior. E estas são questões que concernem inicial e efetivamente à criação de tais valores. E é a isto que se refere a vontade de poder em último caso: à criação dos valores. Considerar a vontade de poder como um desejo de poder seria analisá-la levando em consideração simplesmente os valores em curso já criados, negligenciando, desse modo, a questão da sua criação. Assim, encontramos novamente em "Nietzsche":

É por isso, antes de mais, que é preciso evitar os contra-sensos sobre o princípio nietzscheano de vontade de poder. Este princípio não significa (pelo menos não significa em primeiro lugar) que a vontade queira o poder ou deseje dominar. Enquanto interpretarmos a vontade de poder no sentido de desejo de dominar, fazêmo-la forçosamente depender de valores estabelecidos, os únicos capazes de determinar quem deve ser reconhecido como o mais poderoso neste ou naquele caso, neste ou naquele conflito. Desse modo, ficamos sem conhecer a natureza da vontade de poder como princípio plástico de todas as nossas avaliações, como princípio escondido para a criação de novos valores não reconhecidos. (Deleuze, 2007, p. 23, grifos no original)

Deleuze nos mostra que é sempre possível interpretar a vontade de poder como um desejo de reconhecimento de valores, mas isso já seria uma interpretação que privilegiaria as forças reativas, algo que provavelmente não seria a intenção de Nietzsche quando da formulação de seu conceito. Além disso, dizer que a vontade de poder concerne essencialmente à criação dos valores não seria de forma alguma contradizer a obra de Nietzsche. Uma vontade de poder negativa não se caracterizaria necessariamente por um caráter simplesmente recognitivo: é sempre possível criar novos valores reativos como, por exemplo, valores que se pressupõem superiores à vida.

Não que o reconhecimento dos valores em curso não interessasse ao pensador alemão: Nietzsche sempre denunciou em sua obra a afeição das forças reativas pelo reconhecimento dos valores vigentes, e é justamente por isso que 
ele as considerava como forças predominantemente de conservação. Mas a pedra de toque da crítica nietzschiana diz respeito ao elemento diferencial por meio do qual os valores são criados. "O problema crítico é o valor dos valores, a avaliação da qual procede o valor deles, portanto, o problema de sua criação" (Deleuze, 1976, p. 1, grifo no original).

Sendo assim, a vontade de poder, quando referida ao problema da criação dos valores, diz respeito também a um querer, mas de outro tipo: não um querer relacionado ao poder, mas um querer interno da força. Esse querer interno da força pode ser afirmativo ou negativo, como dito anteriormente. Já podemos deduzir então que uma vontade de poder afirmativa é característica das forças ativas, sendo que uma vontade de poder negativa é própria das forças reativas. E, da mesma forma que as forças reativas não deixam de ser forças, uma vontade de poder negativa não deixa de ser, ainda assim, uma vontade.

Uma vontade de poder afirmativa concerne a uma força que afirma sua diferença de imediato, coisa que se pode verificar facilmente nas forças ativas. Ao contrário, uma vontade de poder negativa diz respeito a uma força que somente afirma sua diferença por meio de uma negação primordial. É por isso que a ação das forças reativas consiste em negar as forças ativas, em reagir a estas forças. Isto se deve justamente ao fato de que a vontade de poder que caracteriza as forças reativas é uma vontade negativa, uma vontade de depreciação. Apesar de haver uma correlação entre as tipologias das forças e das vontades, Deleuze ressalta a importância de não confundirmos esses conceitos, já que eles tratam efetivamente de coisas diferentes.

Ora, se devemos atribuir a maior importância a esta distinção entre duas espécies de qualidades, é porque ela se encontra sempre no centro da filosofia de Nietzsche; entre a ação e a afirmação, entre a reação e a negação, há uma afinidade profunda, uma cumplicidade, mas nenhuma confusão. Além disso, a determinação dessas afinidades põe em jogo toda a arte da filosofia. Por um lado é evidente que há afirmação em toda ação, que há negação em toda reação. Mas, por outro lado, a ação e a reação são antes meios, meios ou instrumentos da vontade de poder que afirma e que nega: as forças reativas, instrumentos do niilismo. Por outro lado ainda, a ação e a reação necessitam da afirmação e da negação como algo que as ultrapassa, mas que é necessário para que realizem seus próprios objetivos. (Deleuze, 1976, p. 44)

A importância do conceito de vontade de poder para Deleuze diz respeito a sua crítica ao pensamento representacional - praticamente toda história da vontade de conhecer -, mas mais especificamente sua crítica à filosofia hegeliana, notadamente à dialética. A diferença, em Hegel, se caracterizaria por um movimento negativo, na medida em que ela somente é atingida por meio da contradição: é necessário que o Ser negue, inicialmente, tudo 
aquilo que ele não é para, desse modo, afirmar sua diferença. Deleuze nos mostra então como o pensamento hegeliano é predominantemente reativo ou composto de forças reativas. Em sua filosofia Hegel não exprime nada além de forças reativas que servem de instrumento a uma vontade de poder negativa, vontade que somente consegue afirmar sua diferença à custa de um movimento essencialmente negativo.

Deleuze nos mostra como isto pode ser observado também no célebre exemplo dialético do senhor e do escravo, bastante utilizado por Hegel. A relação entre o escravo e o senhor não é de forma alguma essencialmente dialética, pelo menos do ponto de vista de um pensamento da diferença. O que interessa ao senhor é estabelecer sua diferença enquanto expressão de uma vontade de poder fundamentalmente afirmativa, ou seja, criar seus próprios valores. Se a relação se torna dialética é somente de acordo com o ponto de vista do escravo. A ação do escravo consiste em negar tudo que é afirmado em primeiro plano pelo senhor. Assim, sua ação consiste simplesmente em uma re-ação, reação que serve de veículo a uma vontade de poder negativa, depreciativa.

O escravo não consegue criar seus próprios valores, reconhecendo somente os valores do senhor e, por isso, atribuindo-lhe a culpa de sua condição. É exatamente por isso que Nietzsche diz que o escravo jamais deixa de ser escravo, mesmo quando consegue tomar o lugar do senhor, pois suas forças são essencialmente reativas. A vontade de poder, em uma perspectiva representacional, é realmente entendida como um desejo de poder: o escravo deseja tomar o poder do senhor porque consegue apenas reconhecer seus valores e mantê-los. E, até mesmo quando o escravo consegue por fim criar seus próprios valores, estes valores são gerados em oposição aos valores do senhor. Eles continuam atestando a criação de uma vontade de poder negativa, uma vontade que só consegue afirmar ou criar por meio de uma depreciação, de uma subtração das forças ativas.

$\mathrm{Na}$ verdade o célebre aspecto dialético da relação senhor-escravo depende de que o poder é aí concebido não como vontade de poder, mas como representação do poder, como representação da superioridade, como reconhecimento por "um" da superioridade do "outro". O que as vontades querem, em Hegel, é fazer reconhecer seu poder, representar seu poder. Ora, segundo Nietzsche, aí reside uma concepção totalmente errônea da vontade de poder e de sua natureza. Tal concepção é a do escravo, ela é a imagem que o homem do ressentimento faz do poder. É o escravo que só concebe o poder como objeto de uma recognição, matéria de uma representação, o que está em causa numa competição e, portanto, o faz depender no fim do combate, de uma simples atribuição de valores estabelecidos. (Deleuze, 1976 , p. 8, grifos no original) 
O que Deleuze deseja evidenciar por meio da obra de Nietzsche é não somente o triunfo do pensamento representacional na história da cultura ocidental, mas principalmente a vida reativa que se lhe encontra associada. $\mathrm{O}$ pensamento deixa de ser uma força criadora para se transformar em aparelho de observar e registrar, de entranhas congeladas. Se o pensador alemão já falava em uma vitória das forças reativas e de uma vida reativa, o filósofo francês nos mostra como esse caráter reativo está correlacionado, por sua vez, a um pensamento reativo, um pensamento que esqueceu o movimento primeiro da criação, que se pauta pelo já criado e naturalizado, e que, desta forma, caracteriza-se pela busca do conhecimento do que já existe, transformando tal reconhecimento ou representação de valores em verdades consideradas superiores. Esse predomínio das forças reativas no pensar acarreta algumas consequências. Da mesma forma que as forças reativas depreciam e aniquilam a vida, separando-a daquilo que ela pode, podemos observar esse mesmo efeito no pensamento: as forças reativas subtraem as forças ativas do pensamento, separando-o assim de sua potência criadora. A atividade do pensamento se torna então predominantemente re-ativa, e o seu objetivo não passa agora de um desejo de re-conhecimento.

\section{Para concluir}

O pensamento de Nietzsche na filosofia de Deleuze é importante pelo fato de que o filósofo francês encontra, no pensador alemão, um formidável aliado na constituição de seu pensamento da diferença. Em "Nietzsche e a filosofia", percebemos como Deleuze se apropria da articulação dos conceitos de força, sentido e valor existentes na obra de Nietzsche para nos apontar uma filosofia perspectivista. Deleuze nos diz que foi Nietzsche quem realizou a verdadeira crítica ao conhecimento. Mas não em nome de novos conhecimentos que seriam os mais verdadeiros. Sua crítica se dirige à raiz, na crítica à criação dos próprios valores, evidenciando que o conhecimento verdadeiro, que sua busca, seu desejo, é proveniente de uma determinada força, e que ao ser elaborado tornou-se uma criação, criação de uma determinada força, de uma determinada vontade.

Quem? Quem quer o verdadeiro? Em várias das suas obras, Deleuze realiza uma crítica ferrenha ao platonismo e à representação. $\mathrm{O}$ pensamento representacional é sempre segundo. Ele sempre se realiza sobre objetos e sujeitos criados, produzidos, naturalizados. Mas Deleuze vai além. Ou melhor, afirma e deixa emergir suas próprias forças. Ao realizar suas análises críticas, o 
filósofo francês confere um novo sentido a conceitos como essência e verdade, conceitos que se encontram no âmago do pensamento representacional.

Do ponto de vista do pensamento representacional o conceito de essência se traduz por suas relações com a identidade: a essência é aquilo que é idêntico a si próprio, a coisa em si. Determinar a essência de algo é então determinar a sua verdade atemporal e imutável. Mas a filosofia de Nietzsche nos mostra que toda e qualquer coisa é justamente o produto arbitrário de determinadas relações de força. A essência não é nada mais do que isso: na origem de algo já havia a apropriação de uma força por outra força, a determinação de um novo sentido por trás de um sentido. Isto não significa negar os conceitos de essência e verdade, mas atribuir-lhes um novo significado.

Desse modo, Deleuze nos mostra como na tradição representacional, notadamente no seu primeiro grande criador, Platão, a pergunta-chave era "que": que é a coragem, que é a justiça, que é a verdade. "Que" era a pergunta que reinava em todos os diálogos socráticos. Por meio dessa pergunta seria possível atingir a verdadeira natureza das coisas, do mundo e dos homens, e esta seria a tarefa principal do filósofo. Mas o pensador-médico, o pensadorintérprete prefere a questão "quem" ou "o que": A quem interessa uma essência imutável? O que deseja alguém ao conferir um sentido imutável a um fenômeno? Se um conceito é a expressão de um sintoma, para quem ele é um sintoma sadio e para quem ele assinala a manifestação de uma "doença"?

A arte pluralista não nega a essência, ela a faz depender em cada caso de uma afinidade de fenômenos e de forças, de uma coordenação de força e de vontade. A essência de uma coisa é descoberta na força que a possui e que nela se exprime, desenvolvida nas forças em afinidade com esta, comprometida ou destruída pelas forças que nela se opõem e que podem prevalecer: a essência é sempre o sentido e o valor. (Deleuze, 1976, p. 63)

Assim, em "Nietzsche e a filosofia" encontramos também a ideia do pensador clinico, do pensador que deve considerar os fenômenos enquanto uma sintomatologia e, então, interpretá-los, conferindo-lhes um sentido. Desse modo, a atividade crítica do pensador jamais se encontra separada de uma atividade clínica: o pensador ou filósofo é, antes de tudo, um médico do mundo. Por meio de sua atividade ele não somente diagnostica os sinais e as forças envolvidas naquilo que poderia se apresentar como uma doença da vida e do pensamento, como também efetua uma prática que tem por objetivo restituir-lhes a saúde, potencializando forças ativas, criando novas possibilidades para ambos. Lembramos que esta ideia permanecerá ao longo 
de toda a obra de Deleuze sendo que seu último livro - "Crítica e clínica" (2008) - é inteiramente dedicado a esta questão. ${ }^{2}$

Mas em "Nietzsche e a filosofia" vemos aparecer, igualmente, a ideia do pensador artista, ideia que será bastante desenvolvida nos livros posteriores do filósofo francês como, por exemplo, "Proust e os signos" (2006). Do ponto de vista de Nietzsche, a arte se apresenta como superior à ciência não pelos seus efeitos, seus produtos, pois ambas criam, mas na medida em que o artista é aquele que perdura na singularidade da sua criação. Singular e universal, universal porque singular, ele não somente explora, mas, por meio de seu trabalho, cria irrepresentáveis. O artista é aquele capaz de captar as diferentes forças existentes, interpretando-as, dando-lhes um sentido e criando assim sua obra de arte. E mediante essa obra o artista afirma sua própria vida, o seu próprio pensamento. "Segundo Nietzsche ainda não se compreendeu o que significa a vida de um artista: a atividade dessa vida que serve de estimulante para a afirmação contida na própria obra-de-arte, a vontade de poder do artista enquanto tal" (Deleuze, 1976, p. 84).

Por fim, em "Nietzsche e a filosofia" vemos aparecer pela primeira vez o tema das imagens do pensamento, problemática central da obra do filósofo francês. Deleuze considera que um pensamento possui certas coordenadas ou eixos de orientação que permitem associá-lo a um determinado modo de funcionamento. Isto significa dizer que estas coordenadas originam imagens do que seria o pensamento, sua natureza ou finalidade. O privilégio atribuído a esta problemática tinha como motivo principal o fato de que para Deleuze estas imagens forneceriam de antemão uma determinada concepção do pensamento bem como as forças que o engendraram e que nele permanecem e, assim, orientando não somente o pensar, mas também a produção do conhecimento e da vida nos mais diversos domínios como a ciência, a arte e principalmente a filosofia.

Por certo esta questão já se encontrava, de algum modo, em "Empirismo e subjetividade" (2008), primeiro livro do autor. Nesse livro, Deleuze se utiliza do empirismo humiano para mostrar um pensamento e um sujeito que advêm das relações existentes entre certos princípios da natureza. Porém essas relações não possuem jamais um caráter representativo: elas somente adquirem seu valor a partir das experiências dos corpos. Assim, ao afirmar nesse texto que pensamento e sujeito se constituem por meio de experiências ou práticas

2 "Fim último da literatura: pôr em evidência no delírio essa criação de uma saúde, ou essa invenção de um povo, isto é, uma possibilidade de vida" (Deleuze, 2008, p. 15). 
que são imanentes aos corpos, o filósofo francês está na verdade afirmando uma concepção do pensamento que se contrapõe à imagem representacional. ${ }^{3}$

Entretanto, em "Nietzsche e a filosofia", a problemática das imagens do pensamento adquire conotações e ligações bem mais explícitas com o corpo/ forças, traduzidas na forma de uma crítica incisiva à imagem representacional do pensamento. Deleuze se utiliza da tipologia nietzschiana das forças para mostrar que as características atribuídas ao pensamento no modelo da representação - a correlação existente entre pensamento e verdade, o caráter recognitivo do pensamento e, principalmente, o pensamento como exercício natural de uma faculdade - são características provenientes de forças reativas.

O mais curioso nessa imagem do pensamento é a maneira pela qual o verdadeiro é, aí, concebido como universal abstrato. Nunca se faz referência às forças reais que fazem o pensamento, nunca se relaciona o próprio pensamento com as forças reais que ele supõe enquanto pensamento. (Deleuze, 1976, p. 85, grifos no original)

Se o filósofo francês se preocupa em mencionar outro tipo de forças, forças reais que fariam efetivamente o pensamento, isso se deve justamente ao fato de que o pensamento não se esgotaria em uma atividade puramente reflexiva, contemplativa e rememorativa. A recognição é com certeza uma das atividades do pensamento, mas uma atividade predominantemente reativa e secundária, ou seja, atividade de um pensamento já separado daquilo que ele efetivamente pode. No entanto, existe outro tipo de forças - forças ativas capazes de desencadear uma atividade diferente no pensamento, forçando-o efetivamente a uma ação, a um ato de pensar, dando a esta atividade uma intensidade, uma vitalidade antes inimaginável.

Pensar é uma n...potência do pensamento. É preciso ainda que ele seja elevado a essa potência, que se torne "o leve", "o afirmativo", "o dançarino". Ora, ele nunca atingirá essa potência se as forças não exercerem uma violência sobre ele. É preciso que uma violência se exerça sobre ele enquanto pensamento, é preciso que um poder force-o a pensar, lance-o num devir ativo. (Deleuze, 1976, p. 89)

Assim, em "Nietzsche e a filosofia", observamos o surgimento de várias questões concernentes à problemática do pensamento, questões que serão amplamente exploradas nos livros seguintes do filósofo francês, ganhando

3 "Fala-se frequentemente de uma crítica das relações em Hume; apresentam-nos a teoria do entendimento como uma crítica das relações. Na verdade, não é a relação que se encontra submetida à crítica, mas a representação, a respeito da qual Hume nos mostra que ela não pode ser um critério para as próprias relações. Estas não são o objeto de uma representação, mas os meios de uma atividade. A mesma crítica que retira a relação da representação, transfere-a à prática" (Deleuze, 2008, p. 137, grifos no original). 
contornos mais bem definidos. Dessa maneira, é interessante observar de que modo Nietzsche se constitui em um dos principais intercessores de Deleuze, não somente por este encontrar no filósofo alemão um aliado no combate à representação, mas, principalmente, pelo fato de o filósofo francês encontrar no perspectivismo nietzschiano um dos principais elementos para a constituição e o desenvolvimento de seu próprio pensamento da diferença, da multiplicidade, da intensidade.

\section{Referências}

DELEUZE, G. "Crítica e clínica". São Paulo: Editora 34, 2008. 171 p. . "Diferença e repetição". São Paulo: Graal, 2009. 437 p. . "Empirismo e subjetividade". São Paulo: Ed. 34, 2008. 153 p. . "Nietzsche". Lisboa: Edições 70, 2007. 106 p. . "Nietzsche e a Filosofia". Rio de Janeiro: Ed. Rio, 1976. 170 p. . "Proust e os signos". Rio de Janeiro: Forense Universitária, 2006. 173 p. NIETZSCHE, F. "Gaia Ciência". Tradução, notas e Posfácio de Paulo César de Souza. São Paulo: Companhia das letras, 2005. 363 p. 